\title{
Rapid Determination of the $S-N$ Curve for Steel by means of the Thermographic Method
}

\author{
Adam Lipski \\ Faculty of Mechanical Engineering, UTP University of Science and Technology in Bydgoszcz, Aleja Profesora S. Kaliskiego 7, \\ 85-796 Bydgoszcz, Poland
}

Correspondence should be addressed to Adam Lipski; adam.lipski@utp.edu.pl

Received 6 December 2015; Revised 24 March 2016; Accepted 31 March 2016

Academic Editor: Paolo Ferro

Copyright (C) 2016 Adam Lipski. This is an open access article distributed under the Creative Commons Attribution License, which permits unrestricted use, distribution, and reproduction in any medium, provided the original work is properly cited.

The paper presents a thermographic method of accelerated determination of the $S$ - $N$ curve. In the presented method, the $S$ - $N$ curve was developed based on energy-related parameter with the assumption of its dependency on the stress amplitude. The tests made on $\mathrm{C} 45$ steel and $\mathrm{X} 5 \mathrm{CrNi18}-10$ steel under reversed bending revealed that the $S-N$ curve obtained by accelerated thermographic method fits inside the $95 \%$ confidence interval for the $S-N$ curve obtained from the full test.

\section{Introduction}

The $S$ - $N$ curve is the basic parameter defining fatigue strength properties of the material under cyclic load, particularly in the case of the so-called stress approach. The fatigue tests are long-lasting and expensive. For example, the minimum number of specimens required to obtain the $S$ - $N$ curve depends on the type of test program conducted and ranges from 12 to 24 for data on design allowables or reliability data (ASTM E 739 91 (reapproved 2004)). This requires testing of specimens at tens or hundreds of thousands of cycles, which significantly influences duration of tests. A test of an individual specimen depends on load frequency and can last even several days, thus making it expensive as well. Hence researchers struggle to develop new methods or to improve existing ones for rapid determining of $S-N$ curve. Thanks to those methods it is possible to significantly cut cost of fatigue tests by reduction of the quantity of specimens and shortening test duration.

Thanks to modern, fast, and high sensitivity thermographic cameras it is possible to record surface temperature distribution of the tested object (specimen) and thus obtain among other things new information about physical phenomena connected with loading and the change of strain state in structural members. This research focuses on phenomena related to temperature changes induced by monotone tension and compression load (e.g., [1-3]) and fatigue load under both uniaxial and multiaxial loading (e.g., [4-7]). Based on the above and other works it is possible to introduce new strength testing methods, including those related to the fatigue of materials and structures.

The effect of temperature changes induced by fatigue loading was initially used for development of accelerated methods for determining fatigue limit. The researcher who first used thermography to determine a surface temperature distribution of a tested specimen and thereby determine the fatigue limit was Risitano [8]. The method proposed by him was used or modified, among others, in the studies [9-12]. According to a similar concept, the fatigue limit is determined using the lock-in method $[13,14]$. In these studies, the fatigue limit is usually determined for the axial load based on the assumption that there is a temperature stabilization period in Phase 2 of the fatigue life (Figure 1, line A). Luong $[9,10]$ has also applied Risitano's methodology to determine the fatigue limit of XC55 steel under four-point rotating bending at $100 \mathrm{~Hz}$ loading frequency.

The temperature evolution can be used for fatigue life prediction. Huang et al. [15] showed that for materials with high ductility under rotating bending the slope of the temperature rise at the beginning of Phase 3 (Figure 1) can be correlated to the fatigue life. The presented methodology may be useful for terminating the operation of machinery in order to prevent catastrophic failure. Jiang et al. [16] showed that 


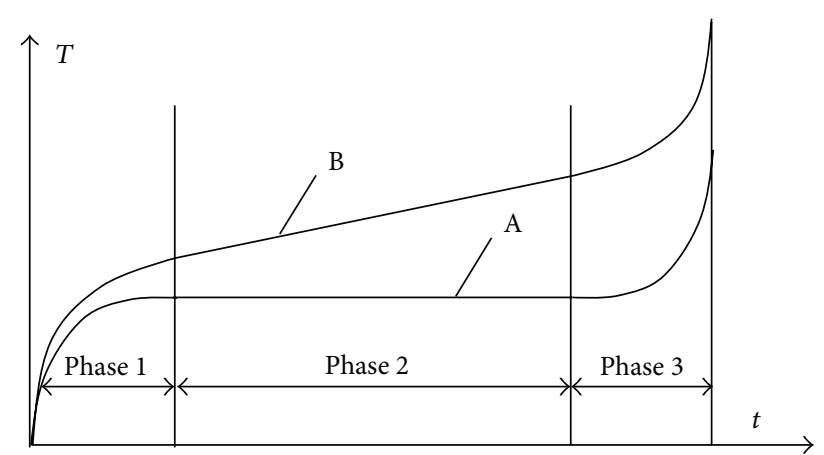

FIGURE 1: The change in the temperature $T$ during the fatigue test for material featuring Phase 2 temperature stabilization (curve A) and a constant rate of temperature rise (curve B) ( $t$ : time).

the life of specimen undergoing axial fatigue load is related to the temperature rise from the initial temperature. Jiang et al. suggested that the temperature rise during Phase 2 can be used as an index of fatigue life. However, it is inapt for some materials that do not exhibit steady-state temperature in Phase 2 [17]. Meneghetti [18] presented a technique for assessment of fatigue life, which involves measuring the cooling rate correlated to the specific heat energy after a sudden interruption of the fatigue test. He showed that fatigue life is correlated to the specific heat energy.

Effects of temperature changes induced by fatigue loading can be used for development of accelerated methods for determining the fatigue $S-N$ curve. Fargione et al. [19] proposed for uniaxial loading that the integration of the area under the temperature rise curve over the entire number of cycles of a specimen (area under curve A, Figure 1, especially under curve $A$ in Phase 2) remains constant and is independent of the stress amplitude, thus representing a characteristic of the material. Amiri and Khonsari $[20,21]$ used the rate of temperature rise in Phase 1 for prediction of fatigue failure.

However not all materials show temperature stabilization period during fatigue life in Phase 2. That was observed, for example, by Krewerth et al. [22], Plekhov et al. [23], and Wang et al. [24]. This fact significantly limited the use of previously developed thermographic methods of rapid determination of the fatigue curve.

A thermographic method for determination of the $S$ $N$ curve was presented in this paper. This method is based on the parameter proposed by Fargione et al. [19] and used in [25-27] but with assumption of its dependency on the stress amplitude as indicated by Crupi et al. [28]. Because this parameter is proportional to energy dissipated under cyclic load which is dependent on the stress level [29] then this assumption seems to be more appropriate.

Application of the proposed method was presented in [30], where it was used to determine the inclination of the $S-N$ curve which is important from the point of view of the accuracy of the fatigue limit determination by the Locati method $[31,32]$. This paper presents the improved version of the analysis of the accelerated test results, allowing outside determination of the inclination of the $S-N$ curve determination of its position on the $S-N$ plane.

\section{Test Description}

2.1. Test Station. The tests were performed at the Department Laboratory for Research on Materials and Structures (certified by the Polish Centre for Accreditation, PCA AB 372) of the Faculty of Mechanical Engineering at the UTP University of Science and Technology using the reversed bending fatigue testing machine (with rotational frequency of $77 \mathrm{~Hz}$ ).

The main item of the test station was the thermographic camera CEDIP Silver 420M (FLIR SC5200) equipped with high sensitivity InSb matrix cooled using Stirling pump.

The main parameters of the camera are as follows: resolution of sensor $320 \times 256$ pixels, spectral range $3.6 \div 5.0 \mu \mathrm{m}$, sensitivity below $20 \mathrm{mK}$ (available: $8 \mathrm{mK}$ ), and maximum frequency $140 \mathrm{~Hz}$ for the entire matrix (up to $25 \mathrm{kHz}$ at lower resolution).

The thermographic camera recorded (at the constant frequency from 100 to $450 \mathrm{~Hz}$ depending on load level) the surface temperature distribution of the tested object (specimen) fixed in the testing machine. Camera images were transmitted via USB interface to PC with appropriate software, where they were digitally stored directly on HDD in form of PTW format files.

The following software was installed on the computer: VirtualCAM allowing two-way communication between PC and the thermographic camera via USB interface, CIRRUS Front End which was the user interface used to control the CEDIP camera, and ALTAIR allowing downloading, storage, and advanced processing of thermographic images.

2.2. Test Specimens. Test specimens were made of cold-drawn bars from the following:

(i) Medium carbon C45 (1.0503) steel.

(ii) Corrosion resistant austenitic X5CrNi18-10 (1.4301) steel.

Chemical composition of the specimen material is specified in Tables 1 and 2. The geometry of applied specimens is shown in Figure 2.

\section{Full Test Results}

3.1. C45 Steel. 21 specimens at 8 load levels were tested for the fatigue $S-N$ curve determination. The lowest alternating stress level $S_{a}$ was $300 \mathrm{MPa}$ and the highest one was $495 \mathrm{MPa}$. The test results and the $S-N$ curve with confidence interval for the significance level $\alpha=0.05$ were presented in Figure 3 .

The Basquin relationship obtained from linear regression $\left(R^{2}=0.98\right)$ of test results is

$$
S_{a}^{m} \cdot N=C
$$

where $m=7.57$ and $C=2.97 \cdot 10^{24}$.

The fatigue limit for this steel obtained from Dixon and Mood relations [33] by Staircase method $S_{e}$ is $261 \mathrm{MPa}$ with standard deviation $s_{s}=9.1 \mathrm{MPa}$. 


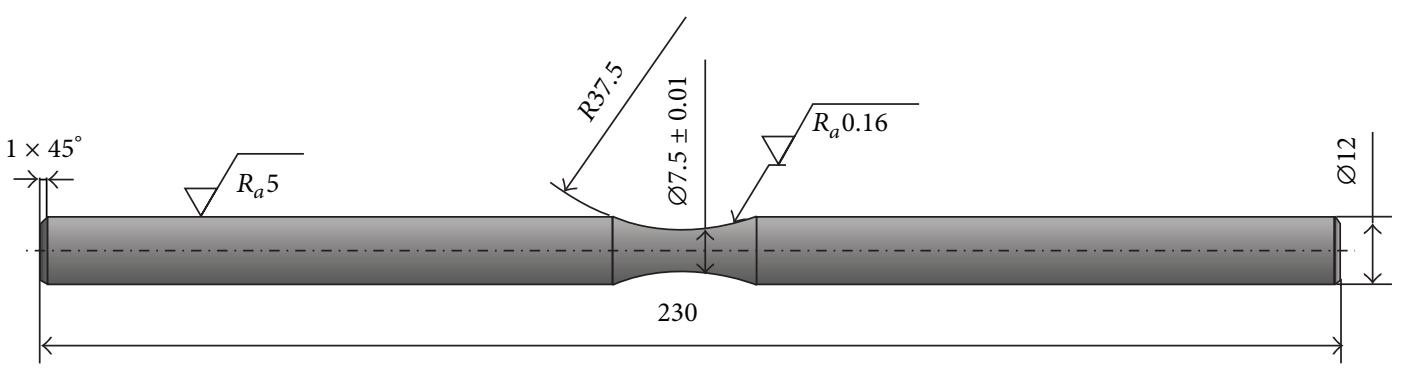

FIGURE 2: Geometry of specimens used for tests.

TABle 1: Chemical composition of the specimens made of C45 steel used for tests (wt\%).

\begin{tabular}{lccccccccc}
\hline & $\mathrm{C}$ & $\mathrm{Si}$ & $\mathrm{Mn}$ & $\mathrm{P}$ & $\mathrm{S}$ & $\mathrm{Cr}$ & $\mathrm{Mo}$ & $\mathrm{Ni}$ & $\mathrm{Cr}+\mathrm{Mo}+\mathrm{Ni}$ \\
\hline Acc. to PN-EN 10083-2:2008 & $0.42-0.50$ & $<0.40$ & $0.50-0.80$ & $<0.045$ & $<0.045$ & $<0.40$ & $<0.10$ & $<0.40$ & $<0.63$ \\
For tested specimens & 0.43 & 0.15 & 0.60 & 0.010 & 0.012 & 0.04 & 0.01 & 0.01 & 0.06 \\
\hline
\end{tabular}

TABLE 2: Chemical composition of the specimens made of X5CrNi18-10 steel used for tests (wt\%).

\begin{tabular}{lcccccccc}
\hline & $\mathrm{C}$ & $\mathrm{Mn}$ & $\mathrm{Si}$ & $\mathrm{P}$ & $\mathrm{S}$ & $\mathrm{Cr}$ & $\mathrm{Ni}$ & $\mathrm{N}$ \\
\hline Acc. to PN-EN 10088-1:2014-12 & $\leq 0.07$ & $\leq 2$ & $\leq 1$ & $\leq 0.045$ & $\leq 0.015$ & $17 \div 19.5$ & $8 \div 10.5$ & $\leq 0.11$ \\
For tested specimens & 0.02 & 1.53 & 0.61 & 0.07 & 0.016 & 18.75 & 8.22 & - \\
\hline
\end{tabular}

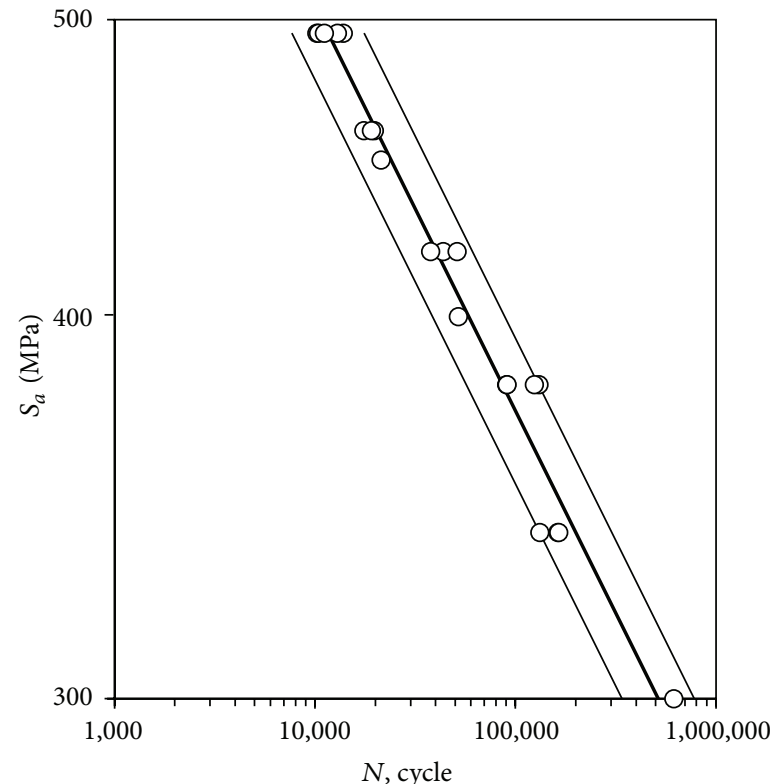

FIGURE 3: The $S$ - $N$ curve for C45 steel under reversed bending.

3.2. X5CrNi18-10 Steel. 18 specimens at 6 load levels were tested for the fatigue $S-N$ curve determination. The lowest alternating stress level $S_{a}$ was $320 \mathrm{MPa}$ and the highest one was $495 \mathrm{MPa}$. The test results and the $S-N$ curve with confidence interval for the significance level $\alpha=0.05$ were presented in Figure 4.

Parameters of Basquin relationship (1) obtained from linear regression $\left(R^{2}=0.98\right)$ of test results are $m=10.38$ and $C=5.12 \cdot 10^{31}$.

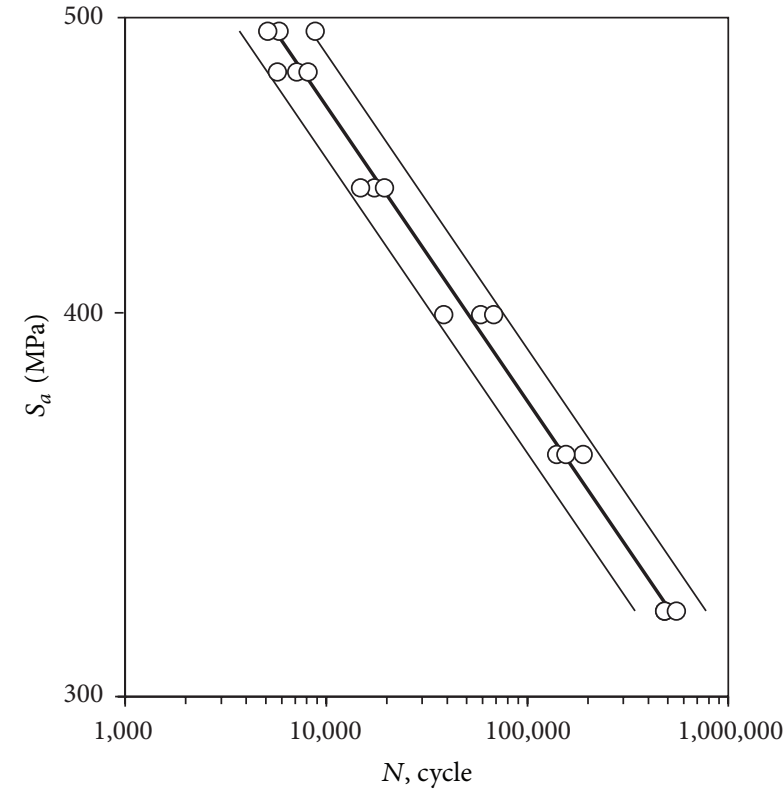

FIgure 4: The $S-N$ curve for X5CrNi18-10 steel under reversed bending.

The fatigue limit for this steel obtained from Dixon and Mood relations [33] by Staircase method $S_{e}$ is $278.2 \mathrm{MPa}$ with standard deviation $s_{s}=7.4 \mathrm{MPa}$.

\section{Full Thermographic Test Results}

4.1. C45 Steel. 21 specimens at 8 load levels were tested using IR camera under constant-amplitude load conditions. The 


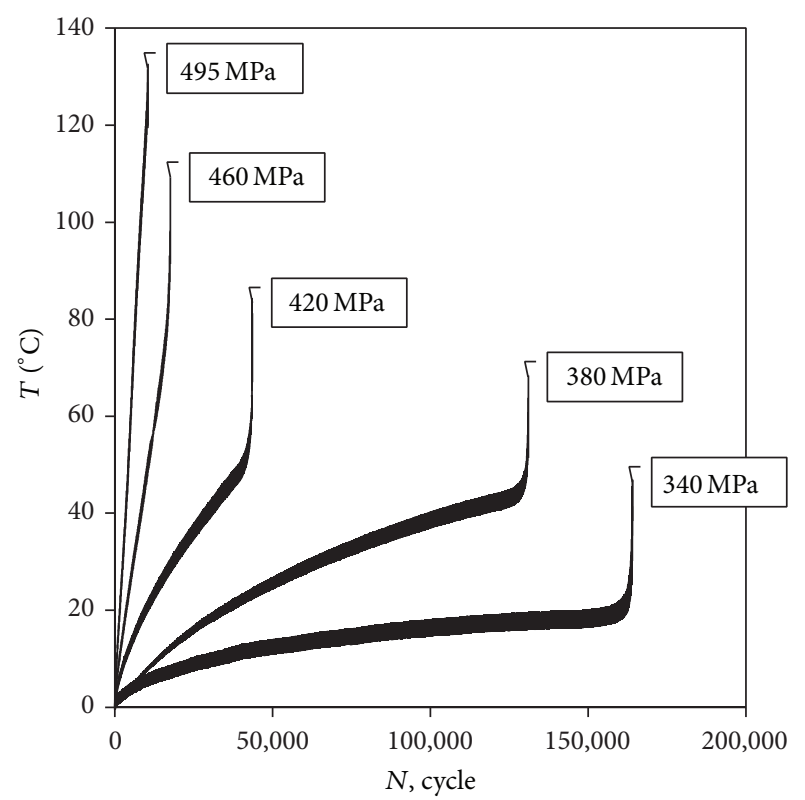

Figure 5: Samples of the $T-N$ curves for C45 steel under reversed bending.

lowest stress amplitude level $S_{a}=300 \mathrm{MPa}$ and the highest one was $495 \mathrm{MPa}$. The change of the surface temperature of selected specimens during tests was presented in Figure 5, where $T=0^{\circ} \mathrm{C}$ for $N=0$ cycles corresponds to the initial specimen temperature of $23-25^{\circ} \mathrm{C}$.

The specimen mean temperature changes presented in Figure 5 result from the internal energy increase which can be estimated based on the following relation:

$$
\Delta I=c_{v} \cdot \rho \int_{0}^{N_{\text {failure }}} T(N) \cdot d N,
$$

where $c_{v}$ is specific heat at constant volume, $\rho$ is density, $d N$ is cycle number increment, and $N_{\text {failure }}$ is number of loading cycles until fatigue failure.

Since $c_{v}$ and $\rho$ can be assumed as constant, then for specimens from the same material the internal energy change can be estimated based on the area under $T=f(N)$ curve (Figure 11):

$$
\Phi=\int_{0}^{N_{\text {failure }}} T(N) \cdot d N .
$$

The dependence of energy-related parameter $\Phi$ on load level $S_{a}$ (Figure 7) was described using the relationship similar to the Basquin formula $\left(R^{2}=0.90\right)$ :

$$
S_{a}^{k} \cdot \Phi=B,
$$

where $k=5.18$ and $B=6.94 \cdot 10^{17}$.

4.2. $\mathrm{X}$ C CrNi18-10 Steel. 12 specimens at 5 load levels were tested using thermographic camera in constant-amplitude loading conditions. The lowest alternating stress level $S_{a}$ was $320 \mathrm{MPa}$ and the highest one was $480 \mathrm{MPa}$.

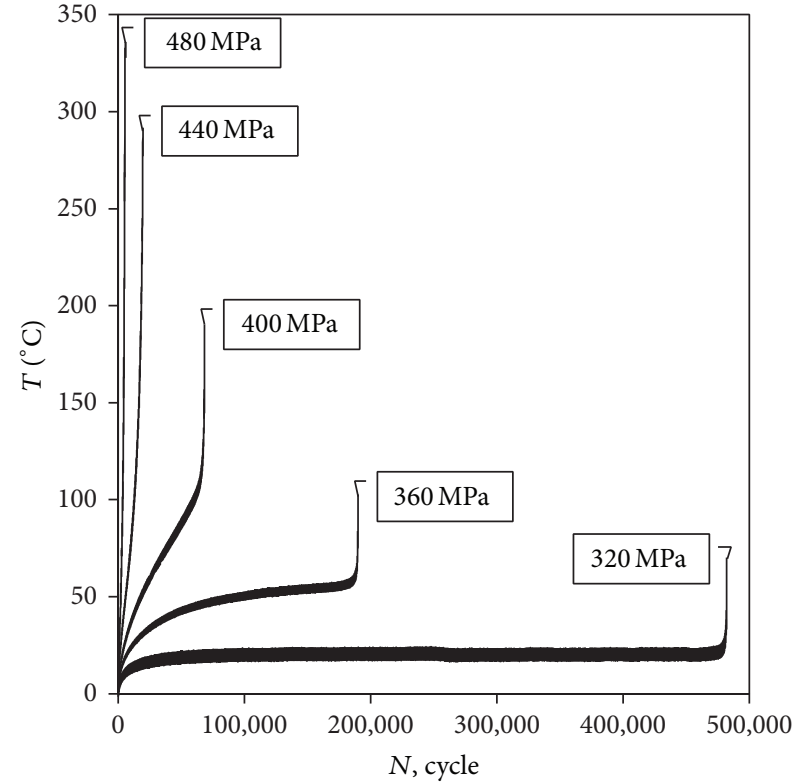

Figure 6: Samples of the $T-N$ curves for X5CrNi18-10 steel under reversed bending.

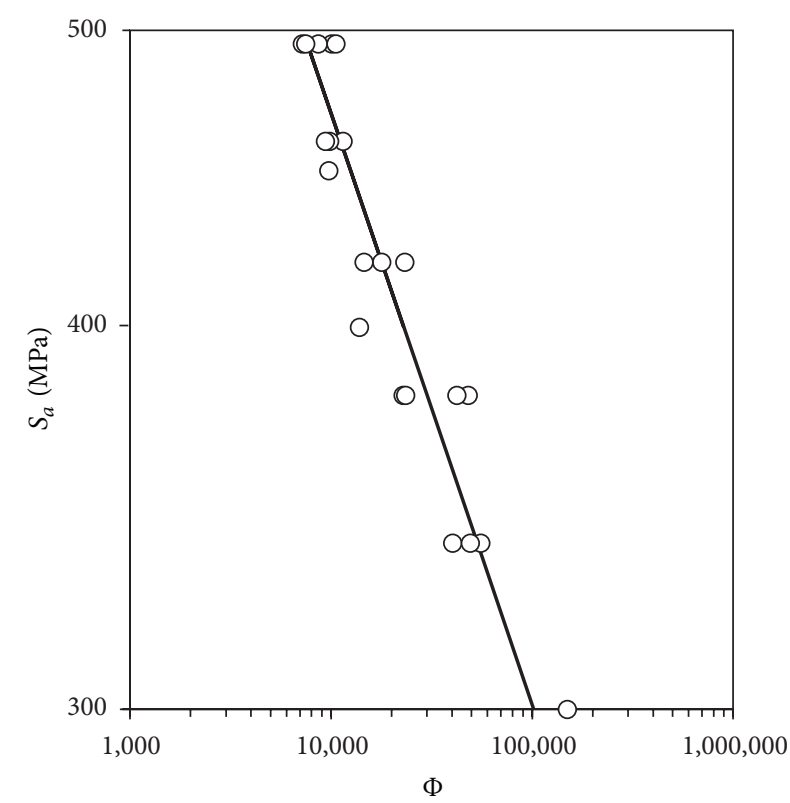

Figure 7: The dependence of $\Phi$ parameter on load level $S_{a}$ for C45 steel under reversed bending.

The change of the surface temperature of selected specimens during tests was presented in Figure 6, where $T=0^{\circ} \mathrm{C}$ for $N=0$ cycles corresponds to initial specimen temperature of $22-25^{\circ} \mathrm{C}$.

The dependence of energy-related parameter $\Phi$ on load level $S_{a}$ was shown in Figure 8 and described using relationship (4) $\left(R^{2}=0.93\right)$ with parameters $k=5.18$ and $B=$ $6.94 \cdot 10^{17}$. 


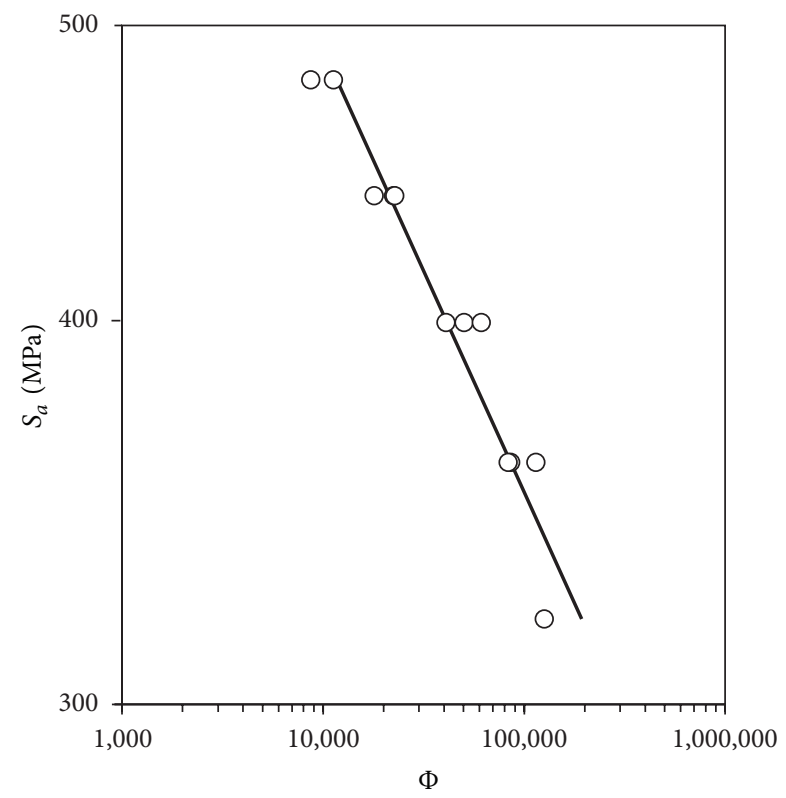

Figure 8: The dependence of $\Phi$ parameter on load level $S_{a}$ for $\mathrm{X} 5 \mathrm{CrNi18}-10$ steel under reversed bending.

TABLE 3: Summary of fatigue life for the individual specimens made of C45 steel in the accelerated tests.

\begin{tabular}{lcccc}
\hline \multicolumn{1}{c}{ Specimen } & & Number 1 & Number 2 & Number 3 \\
\hline Level of fatigue failure & $i$ & 16 & 16 & 15 \\
Failure stress, MPa & $S_{k}$ & 380 & 380 & 370 \\
Total fatigue life, in cycles & $N_{c}$ & 474500 & 475300 & 429800 \\
\hline
\end{tabular}

TABLE 4: Summary of fatigue life for the individual specimens made of X5CrNi18-10 steel in the accelerated tests.

\begin{tabular}{lcccc}
\hline \multicolumn{1}{c}{ Specimen } & & Number 1 & Number 2 & Number 3 \\
\hline Level of fatigue failure & $i$ & 18 & 17 & 16 \\
Failure stress, MPa & $S_{k}$ & 400 & 390 & 380 \\
Total fatigue life, in cycles & $N_{c}$ & 518400 & 487300 & 457600 \\
\hline
\end{tabular}

\section{Accelerated Test Results}

The $S$ - $N$ curve for both steels was determined in gradually increasing loading test. The lowest alternating stress level $S_{a 1}$ was $230 \mathrm{MPa}$ and the stress increment $\Delta S$ amounted to $10 \mathrm{MPa} . \Delta N$ for each load level was 30000 cycles. After each load level the test was stopped for about 30 seconds for the purpose of load increase. The test was made at the same load frequency of $77 \mathrm{~Hz}$ as the full test. The change of the surface temperature of selected specimen during test was presented in Figure 9, where $T=0^{\circ} \mathrm{C}$ for $N=0$ cycles corresponds to initial specimen temperature of $19^{\circ} \mathrm{C}$.

Theoretically, accelerated test can be made using only one specimen, but, in practice, tests on three samples can increase the accuracy of estimates. Tables 3 and 4 show total fatigue life achieved by each sample for both tested materials.

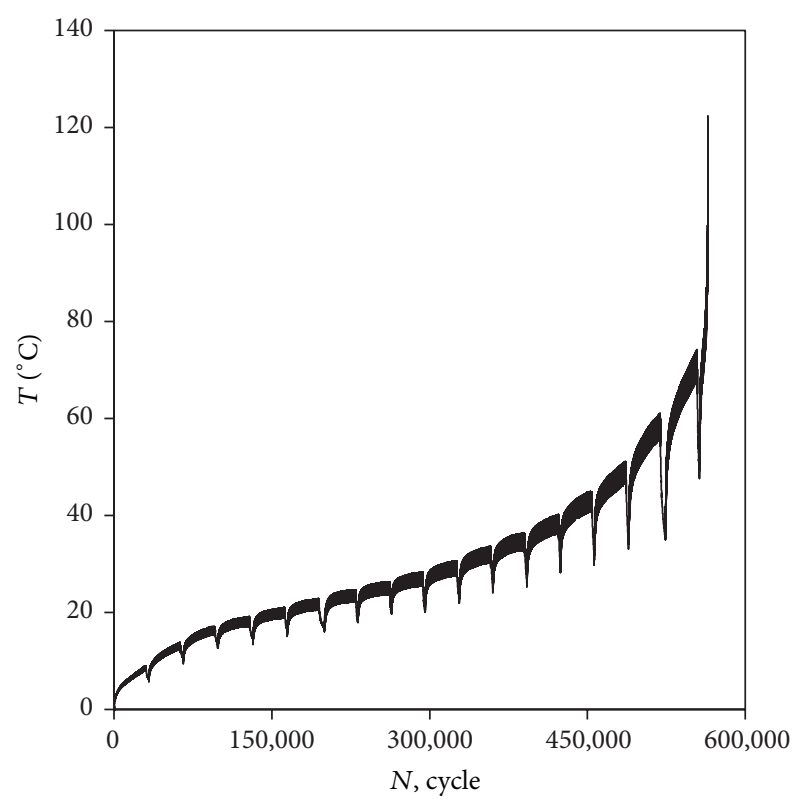

Figure 9: Sample of the $T-N$ curve for $\mathrm{X} 5 \mathrm{CrNi18}-10$ steel under accelerated test.

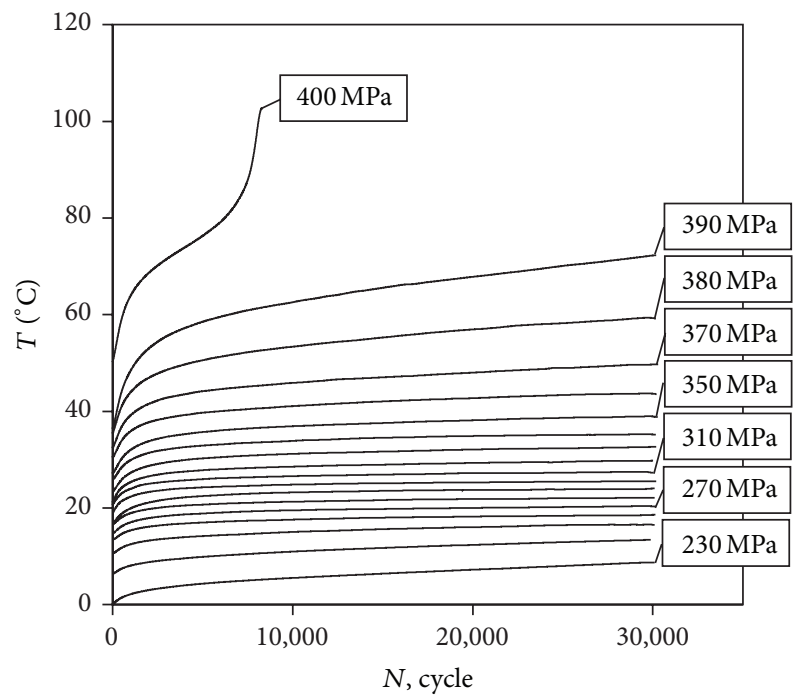

Figure 10: Sample of cut $T-N$ curves for different load levels for specimen from X5CrNi18-10 steel.

\section{Analysis of the Accelerated Test Results}

The $T$-N curve (Figure 9) obtained from gradually increasing loading test was cut into individual $T-N$ curves for the different load levels (Figure 10). The reference level of the temperature was the initial temperature of the specimen.

It was assumed that under the gradually increasing loading test at each load level only part of the total internal energy represented by parameter $\varphi$ was measured (Figure 11):

$$
\varphi=\int_{0}^{N_{\text {step }}} T(N) \cdot d N
$$

where $N_{\text {step }}=\Delta N=30000$ cycles. 


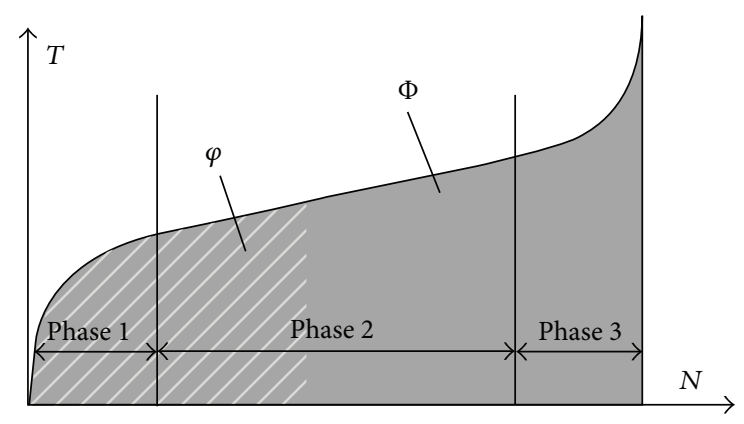

FIGURE 11: Schematic representation of energy-based parameters $\Phi$ and $\varphi$.

Palmgren-Miner's hypothesis in its energy-related version can assume the following form:

$$
\sum_{i=1}^{q} \frac{\varphi_{i}}{\Phi_{i}}=1 \quad \text { for } S_{a i} \geq S_{e}
$$

Assuming that the relationship between energy-related parameter $\Phi_{i}$ for full test and load $S_{a i}$ at the level $i$ is described by formula (4)

$$
\begin{aligned}
S_{a i}^{k} \cdot \Phi_{i} & =B \Longrightarrow \\
\Phi_{i} & =\frac{B}{S_{a i}^{k}}
\end{aligned}
$$

and putting (7) into (6),

$$
\begin{aligned}
& \sum_{i=1}^{q} \frac{\varphi_{i}}{B / S_{a i}^{k}}=1 \Longrightarrow \\
& \sum_{i=1}^{q} S_{a i}^{k} \cdot \varphi_{i}=B
\end{aligned}
$$

is obtained:

$$
\sum_{i=1}^{q} S_{a i}^{k} \cdot \varphi_{i}-B=0
$$

where there are two unknown parameters $B$ and $k$ of the $S_{a}=$ $f(\Phi)$ curve which can be determined numerically. Then it is possible to determine the values of $\Phi_{i}$ at the level $i$ by using (7).

Fatigue life at the level $i$ can be estimated based on the following proportions:

$$
\begin{aligned}
\frac{\varphi_{i}}{\Phi_{i}} & =\frac{n_{i}}{N_{i}} \Longrightarrow \\
N_{i} & =\frac{\Phi_{i}}{\varphi_{i}} \cdot n_{i} .
\end{aligned}
$$

Tables 5 and 6 show parameters (see (1) and (4)) obtained by the presented method for both tested materials.

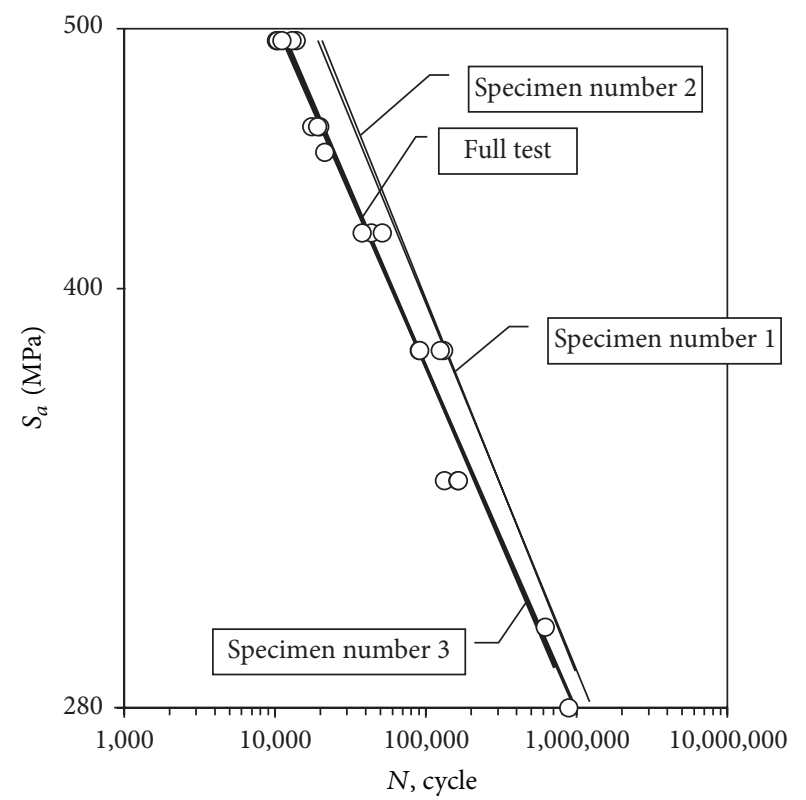

FIGURE 12: The $S$ - $N$ curves estimated for individual specimens made of C45 steel on the background of the full test results.

TABle 5: Parameters obtained for the individual specimens of C45 steel under reversed bending in the accelerated thermographic tests.

\begin{tabular}{lcccc}
\hline & $k$ & $B$ & $m$ & $C$ \\
\hline Full test & 5.18 & $6.94 \cdot 10^{17}$ & 7.57 & $2.97 \cdot 10^{24}$ \\
Specimen number 1 & 5.10 & $7.17 \cdot 10^{21}$ & 7.35 & $1.23 \cdot 10^{24}$ \\
Specimen number 2 & 5.15 & $8.41 \cdot 10^{21}$ & 7.18 & $4.48 \cdot 10^{23}$ \\
Specimen number 3 & 5.27 & $8.40 \cdot 10^{21}$ & 7.66 & $5.15 \cdot 10^{24}$ \\
Specimens numbers 1-3 & - & - & 7.40 & $1.42 \cdot 10^{24}$ \\
\hline
\end{tabular}

TABLE 6: Parameters obtained for the individual specimens of X5CrNil8-10 steel under reversed bending in the accelerated thermographic tests.

\begin{tabular}{lcccc}
\hline & $k$ & $B$ & $m$ & $C$ \\
\hline Full test & 6.914 & $4.03 \cdot 10^{22}$ & 10.377 & $5.12 \cdot 10^{31}$ \\
Specimen number 1 & 6.408 & $4.00 \cdot 10^{21}$ & 10.157 & $2.63 \cdot 10^{31}$ \\
Specimen number 2 & 6.500 & $4.10 \cdot 10^{21}$ & 9.196 & $6.75 \cdot 10^{28}$ \\
Specimen number 3 & 6.500 & $4.00 \cdot 10^{21}$ & 9.456 & $2.30 \cdot 10^{29}$ \\
Specimens numbers 1-3 & - & - & 9.603 & $5.87 \cdot 10^{29}$ \\
\hline
\end{tabular}

The $S$ - $N$ curves estimated for the individual specimens were presented in Figures 12 and 13. The individual estimated fatigue life data obtained from (10) for all three specimens has been used as data to estimate one $S$ - $N$ curve (Figures 14 and 15).

\section{Conclusions}

The presented new thermographic method enables rapid determination of the $S-N$ curve. This method is based on the energy-related parameter with the assumption of its dependency on the stress amplitude. 


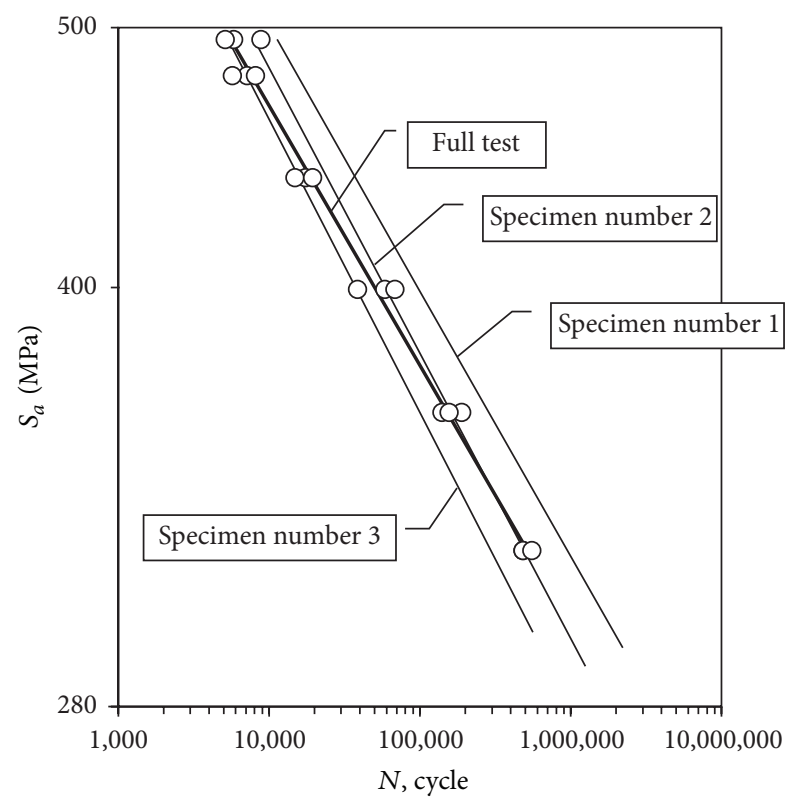

FIGURE 13: The $S$ - $N$ curves estimated for individual specimens made of X5CrNi18-10 steel on the background of the full test results.

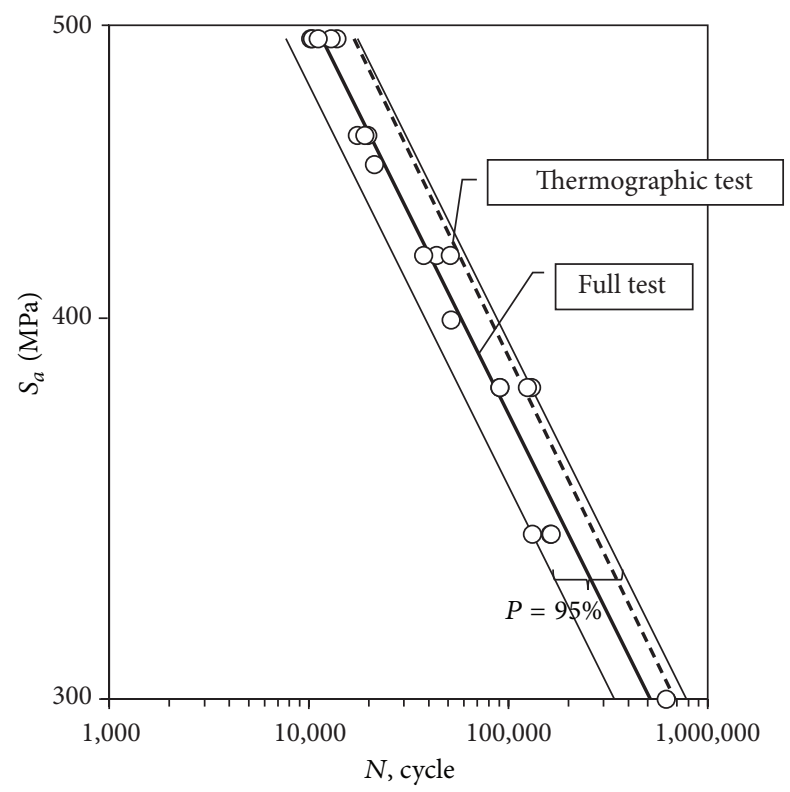

FIGURE 14: Comparison of estimated $S-N$ curves obtained by the accelerated thermographic method and full test for C45 steel.

Major findings and conclusions of the presented tests and analysis are summarized as follows:

(1) The $S-N$ curve obtained by accelerated thermographic method fits inside the $95 \%$ confidence interval for the $S-N$ curve obtained from the full test for both tested steels.

(2) The estimation of the parameters of the $S_{a}-\Phi$ curve and the $S-N$ curve for each specimen for both materials is characterized by repeatability.

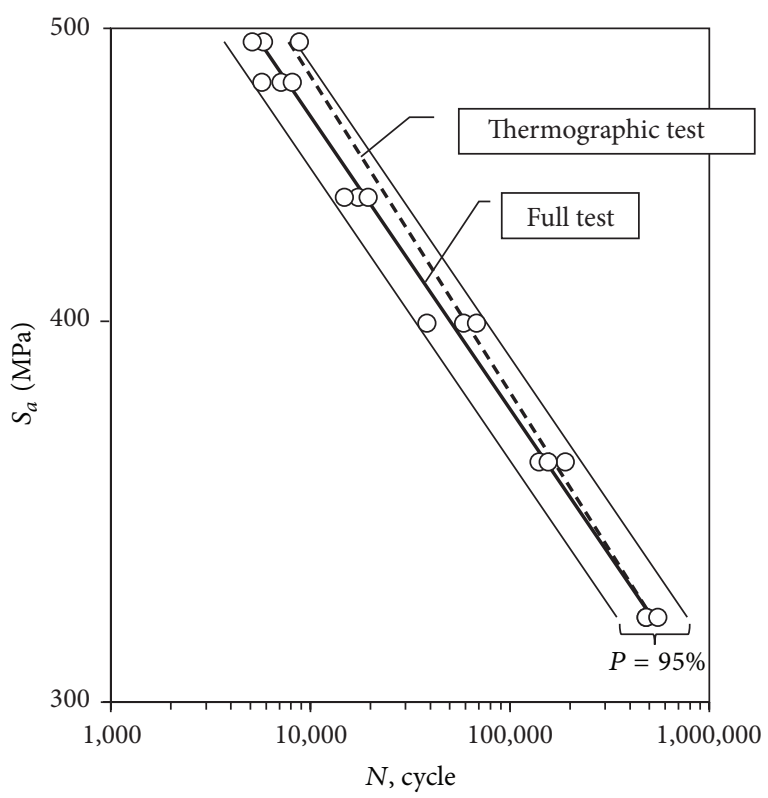

FIGURE 15: Comparison of estimated $S-N$ curves obtained by the accelerated thermographic method and full test for X5CrNi18-10 steel.

(3) The accelerated thermographic test for one specimen lasted ca. 1.5 hours only. For comparison, the full test lasts several days.

(4) The accelerated thermographic test can be made on one specimen. Three specimens for increasing the accuracy of estimates were assumed in this work. The full test requires a minimum of a dozen or so specimens.

\section{Competing Interests}

The author declares that there are no competing interests regarding the publication of this paper.

\section{Acknowledgments}

The publication is financed by the Polish National Centre for Research and Development in the framework of the INNOTECH-IN-TECH program identified as Project no. INNOTECH-K3/IN3/32/227826/NCBR/14.

\section{References}

[1] R. Litwinko and W. Oliferuk, "Yield point determination based on thermomechanical behaviour of polycrystalline material under uniaxial loading," Acta Mechanica et Automatica, vol. 3, no. 4, pp. 49-51, 2009.

[2] A. Lipski, "Impact of the strain rate during tension test on $46 \mathrm{Cr} 1$ steel temperature change," Key Engineering Materials, vol. 598, pp. 133-140, 2014.

[3] A. Lipski and D. Boroński, "Use of thermography for the analysis of strength properties of mini-specimens," Materials Science Forum, vol. 726, pp. 156-161, 2012. 
[4] C. Doudard, M. Poncelet, S. Calloch, C. Boue, F. Hild, and A. Galtier, "Determination of an HCF criterion by thermal measurements under biaxial cyclic loading," International Journal of Fatigue, vol. 29, no. 4, pp. 748-757, 2007.

[5] M. Poncelet, C. Doudard, S. Calloch, B. Weber, and F. Hild, "Probabilistic multiscale models and measurements of selfheating under multiaxial high cycle fatigue," Journal of the Mechanics and Physics of Solids, vol. 58, no. 4, pp. 578-593, 2010.

[6] A. Lipski and D. Skibicki, "Variations of the specimen temperature depending on the pattern of the multiaxial loadpreliminary research," Materials Science Forum, vol. 726, pp. 162-168, 2012.

[7] D. Skibicki, J. Sempruch, A. Lipski, and Ł. Pejkowski, "Fatigue life, fractographic and thermographic analysis of steel X2CrNiMo17-12-2 for proportional and non-proportional loads," in Proceedings of the 10th International Conference on Multiaxial Fatigue \& Fracture, Kyoto, Japan, June 2013.

[8] G. La Rosa and A. Risitano, "Thermographic methodology for rapid determination of the fatigue limit of materials and mechanical components," International Journal of Fatigue, vol. 22, no. 1, pp. 65-73, 2000.

[9] M. P. Luong, "Infrared thermographic scanning of fatigue in metals," Nuclear Engineering and Design, vol. 158, no. 2-3, pp. 363-376, 1995.

[10] M. P. Luong, "Fatigue limit evaluation of metals using an infrared thermographic technique," Mechanics of Materials, vol. 28, no. 1-4, pp. 155-163, 1998.

[11] F. Curà, G. Curti, and R. Sesana, "A new iteration method for the thermographic determination of fatigue limit in steels," International Journal of Fatigue, vol. 27, no. 4, pp. 453-459, 2005.

[12] U. Galietti, D. Palumbo, R. De Finis, and F. Ancona, "Fatigue limit evaluation of martensitic steels with thermal methods," in Proceedings of the 12th International Conference of Quantitative Infrared Thermography (QIRT '14), Bordeaux, France, July 2014.

[13] E. Z. Kordatos, K. G. Dassios, D. G. Aggelis, and T. E. Matikas, "Rapid evaluation of the fatigue limit in composites using infrared lock-in thermography and acoustic emission," Mechanics Research Communications, vol. 54, pp. 14-20, 2013.

[14] X. D. Li, H. Zhang, D. L. Wu, X. Liu, and J. Y. Liu, "Adopting lock-in infrared thermography technique for rapid determination of fatigue limit of aluminum alloy riveted component and affection to determined result caused by initial stress," International Journal of Fatigue, vol. 36, no. 1, pp. 18-23, 2012.

[15] Y. Huang, S. X. Li, S. E. Lin, and C. H. Shih, "Using the method of infrared sensing for monitoring fatigue process of metals," Materials Evaluation, vol. 42, no. 8, pp. 1020-1024, 1984.

[16] L. Jiang, H. Wang, P. K. Liaw, C. R. Brooks, and D. L. Klarstrom, "Characterization of the temperature evolution during highcycle fatigue of the ULTIMET superalloy: experiment and theoretical modeling," Metallurgical and Materials Transactions A, vol. 32, no. 9, pp. 2279-2296, 2001.

[17] M. M. Khonsari and M. Amiri, Introduction to Thermodynamics of Mechanical Fatigue, CRC Press, New York, NY, USA, 2013.

[18] G. Meneghetti, "Analysis of the fatigue strength of a stainless steel based on the energy dissipation," International Journal of Fatigue, vol. 29, no. 1, pp. 81-94, 2007.

[19] G. Fargione, A. Geraci, G. La Rosa, and A. Risitano, "Rapid determination of the fatigue curve by the thermographic method," International Journal of Fatigue, vol. 24, no. 1, pp. 11-19, 2002.
[20] M. Amiri and M. M. Khonsari, "Life prediction of metals undergoing fatigue load based on temperature evolution," Materials Science and Engineering A, vol. 527, no. 6, pp. 1555-1559, 2010.

[21] M. Amiri and M. M. Khonsari, "Rapid determination of fatigue failure based on temperature evolution: fully reversed bending load," International Journal of Fatigue, vol. 32, no. 2, pp. 382-389, 2010.

[22] D. Krewerth, A. Weidner, and H. Biermann, "Application of in situ thermography for evaluating the high-cycle and very highcycle fatigue behaviour of cast aluminium alloy AlSi7Mg (T6)," Ultrasonics, vol. 53, no. 8, pp. 1441-1449, 2013.

[23] O. A. Plekhov, N. Saintier, T. Palin-Luc, S. V. Uvarov, and O. B. Naimark, "Theoretical analysis, infrared and structural investigations of energy dissipation in metals under cyclic loading," Materials Science and Engineering A, vol. 462, no. 1-2, pp. 367-369, 2007.

[24] C. Wang, A. Blanche, D. Wagner, A. Chrysochoos, and C. Bathias, "Dissipative and microstructural effects associated with fatigue crack initiation on an Armco iron," International Journal of Fatigue, vol. 58, pp. 152-157, 2014.

[25] A. Risitano and G. Risitano, "Cumulative damage evaluation of steel using infrared thermography," Theoretical and Applied Fracture Mechanics, vol. 54, no. 2, pp. 82-90, 2010.

[26] X. G. Wang, V. Crupi, C. Jiang, and E. Guglielmino, "Quantitative Thermographic Methodology for fatigue life assessment in a multiscale energy dissipation framework," International Journal of Fatigue, vol. 81, pp. 249-256, 2015.

[27] L. Zhang, X. S. Liu, S. H. Wu, Z. Q. Ma, and H. Y. Fang, "Rapid determination of fatigue life based on temperature evolution," International Journal of Fatigue, vol. 54, pp. 1-6, 2013.

[28] V. Crupi, G. Epasto, E. Guglielmino, and G. Risitano, "Investigation of very high cycle fatigue by thermographyc method," Fracture and Structural Integrity, vol. 30, pp. 569-577, 2014.

[29] G. Grzegorz and M. Stanislaw, "Fatigue life of GX12CrMoVNbN9-1 cast steel in the energy-based approach," Advanced Materials Research, vol. 396-398, pp. 446-449, 2012.

[30] A. Lipski, "Determination of fatigue limit by locati method using S-N curve determined by means of thermographic method," Solid State Phenomena, vol. 223, pp. 362-373, 2015.

[31] L. Locati, "Le prove di fatica come ausilio alla progettazione ed alla produzione," La Metallurgia Italiana, vol. 47, no. 9, pp. 301308, 1955.

[32] N. E. Frost, K. Marsh, and L. P. Pook, Metal Fatigue, Clarendon Press, Oxford, UK, 1974.

[33] W. J. Dixon and A. M. Mood, "A method for obtaining and analyzing sensitivity data," Journal of the American Statistical Association, vol. 43, no. 241, pp. 109-126, 1948. 

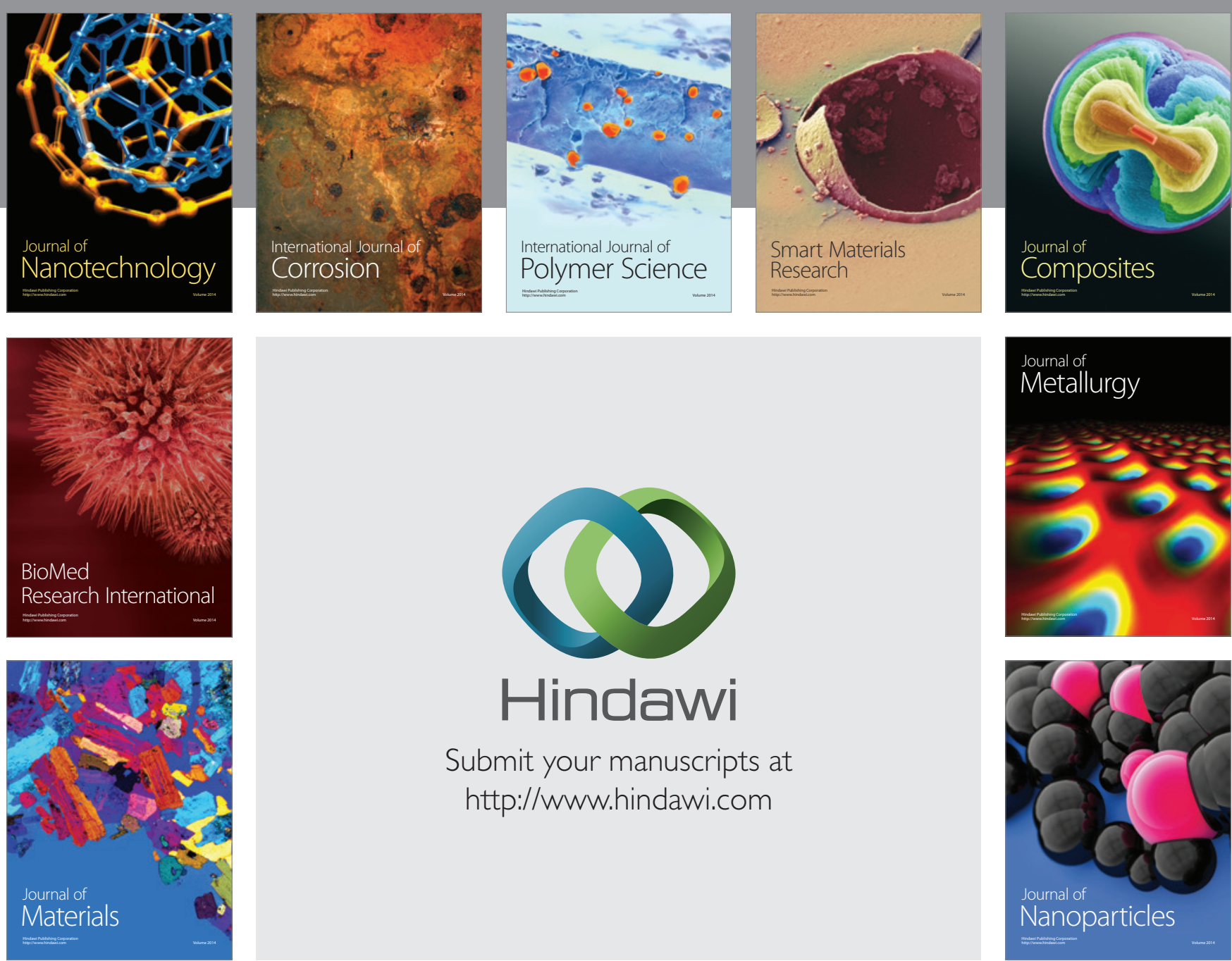

\section{Hindawi}

Submit your manuscripts at

http://www.hindawi.com

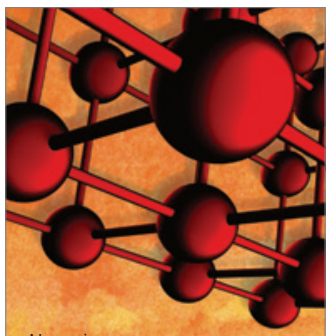

Materials Science and Engineering
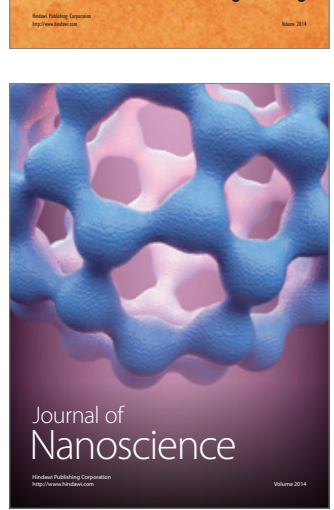
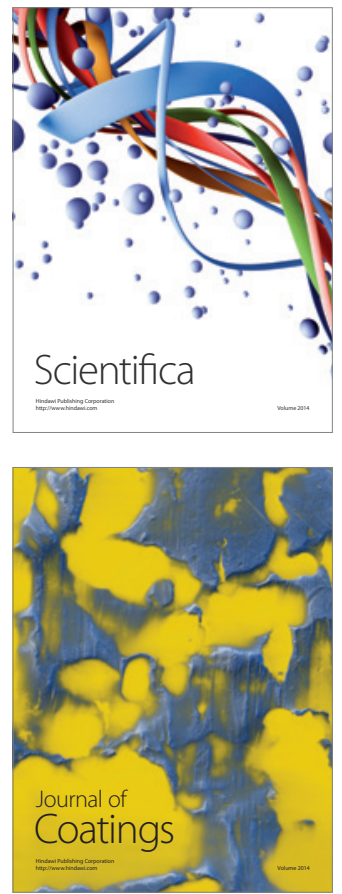
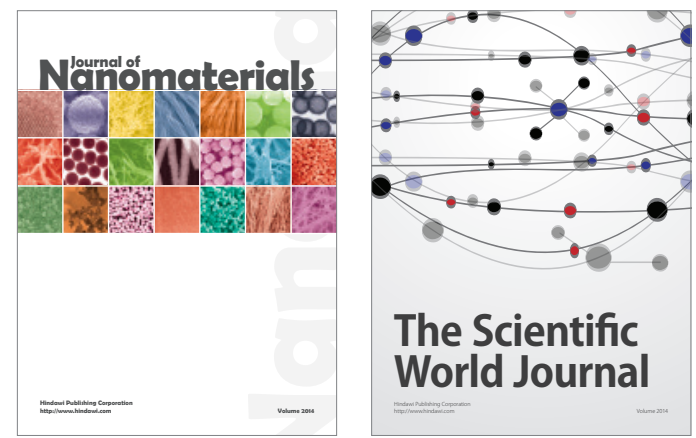

The Scientific World Journal
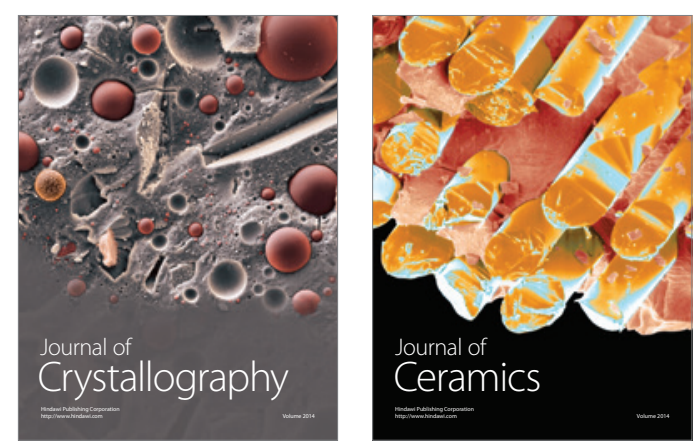
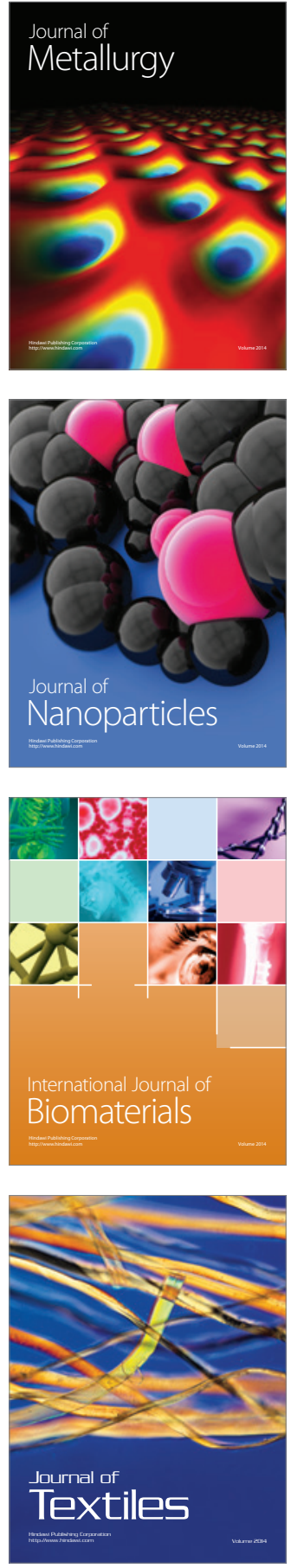